\title{
GEOINFORMATIONAL ANALYSIS OF TRANSPORT ACCESSIBILITY CONDITIONS OF RURAL TERRITORIES OF VOLGOGRAD REGION
}

\author{
Natalya M. Khavanskaya \\ Volgograd State University, Volgograd, Russian Federation \\ Vladimir A. Alyaev \\ Volgograd State University, Volgograd, Russian Federation \\ Diana A. Semenova \\ Volgograd State University, Volgograd, Russian Federation
}

\begin{abstract}
The article deals with the assessment of transport accessibility of rural settlements. The main research methods are the geoinformation and cartographic methods. A transport accessibility factor implies the time spent on moving between villages and the center. The methodology proposed is based on two spatial levels: the district level, where the territory of mapping is the municipal districts of Volgograd region, and the object is rural settlements; the regional level covering the entire territory of the region. At the district level, the calculation and geoinformation analysis of the transport accessibility of villages in relation to district centers are made. As a result, it is identified that the territories are in different conditions of transport accessibility. $20.9 \%$ of the region's villages are located in favorable conditions (transport accessibility less than 30 minutes); $25.2 \%$ of villages are in less favorable conditions (transport accessibility $30-45$ minutes); $53.9 \%$ of villages are in unfavorable conditions (more than 45 minutes). At the regional level in relation to Volgograd, there are three zones with a different degree of favorable transport conditions: a zone of time accessibility up to 2 hours with favorable conditions for economic development; a restrictedly favorable zone with time accessibility of 2-4 hours; and a zone of unfavorable economic influence with the time transport accessibility exceeding 4 hours. It is noted that 15 out of 33 districts of Volgograd region are in unfavorable conditions of transport accessibility in relation to the regional center. This is primarily determined by the size of the region's territory, the geographical location of Volgograd, the state of the road network, namely the presence of asphalt roads. The conclusion is drawn about the heterogeneity of the conditions for the provision of residents with services concentrated in the centers based on the uneven distribution of the conditions of transport accessibility. The authors give recommendations for the development of regional sub-centers of public service.

$\vec{\delta} \quad$ Key words: rural settlement, time transport accessibility, spatial interpolation, geoinformation and cartographic methods, isochron method, transport accessibility zones, Volgograd region.

Citation. Khavanskaya N.M., Alyaev V.A., Semenova D.A. Geoinformational Analysis of Transport Accessibility Conditions of Rural Territories of Volgograd Region. Prirodnye sistemy i resursy [Natural Systems and Resources], 2021, vol. 11, no. 1, pp. 27-34. DOI: https://doi.org/10.15688/nsr.jvolsu.2021.1.4

УДК 528.94:911.373:711

ББК 26.17
\end{abstract}

\section{ГЕОИНФОРМАЦИОННЫЙ АНАЛИЗ УСЛОВИЙ ТРАНСПОРТНОЙ ДОСТУПНОСТИ СЕЛЬСКИХ ТЕРРИТОРИЙ ВОЛГОГРАДСКОЙ ОБЛАСТИ}

\author{
Наталья Михайловна Хаванская \\ Волгоградский государственный университет, г. Волгоград, Российская Федерация \\ Владимир Алексеевич Аляев \\ Волгоградский государственный университет, г. Волгоград, Российская Федерация
}




\title{
Диана Александровна Семенова
}

Волгоградский государственный университет, г. Волгоград, Российская Федерация

\begin{abstract}
Аннотация. Статья посвящена оценке транспортной доступности сельских населенных пунктов с использованием методов геоинформационного картографирования. В качестве фактора транспортной доступности рассматриваются временные затраты на перемещение между селами и центром. Предлагаемая методика оценки основана на двух пространственных уровнях. Районный уровень, где территорией картографирования являются муниципальные районы Волгоградской области, а объектом - сельские населенные пункты. Региональный уровень, охватывающий всю территорию области. На районном уровне проводится расчет и геоинформационный анализ транспортной доступности сел относительно районных центров. В результате выявлены территории, находящиеся в разных условиях транспортной доступности. В благоприятных условиях (транспортная доступность менее 30 минут) расположено 20,9 \% сел региона; в ограниченно благоприятных (транспортная доступность 30-45 минут) - 25,2 \% сел; в неблагоприятных (более 45 минут) 53,9 \% сел. На региональном уровне по отношению в Волгограду выявлены три зоны с разной степенью благоприятности транспортных условий. Зона временной доступности до 2 часов с благоприятными условиями для хозяйственного развития. Ограниченно благоприятная зона с временной доступностью от 2 до 4 часов и зона неблагоприятного хозяйственного влияния, где временная транспортная доступность превышает 4 часа. Отмечено, что 15 из 33 районов Волгоградской области находятся в неблагоприятных условиях транспортной доступности по отношению к региональному центру. Это в первую очередь определяется размерами территории региона, географическим положением Волгограда, состоянием дорожной сети, а именно наличием дорог с асфальтовым покрытием. На основе неравномерного распределения условий транспортной доступности сделан вывод о неоднородности условий обеспеченности жителей услугами, сосредоточенными в центрах. Сформулировано предложение по развитию региональных подцентров обслуживания населения.
\end{abstract}

Ключевые слова: сельское расселение, временная транспортная доступность, пространственная интерполяция, геоинформационно-картографические методы, метод изохрон, зоны транспортной доступности, Волгоградская область.

Цитирование. Хаванская Н. М., Аляев В. А., Семенова Д. А. Геоинформационный анализ условий транспортной доступности сельских территорий Волгоградской области // Природные системы и ресурсы. 2021. - T. 11, № 1. - C. 27-34. - DOI: https://doi.org/10.15688/nsr.jvolsu.2021.1.4

\section{Введение}

Понятие транспортной доступности является одним из составляющих комплексной социально-экономической оценки территорий. В социально-экономической науке существуют различные подходы к оценке транспортной доступности, среди которых можно отметить: расчет расстояния между периферийными населенными пунктами и центром [16], расчет временных затрат в пути [9] между населенными пунктами или другими точками интереса, построение графов [17] на основе дорожной сети, расчет стоимостных расходов на поездку [12], густота дорожно-транспортной сети [3] и т. д. В обобщенном виде описанные в научной литературе методы [5] условно можно разделить на математико-статистические и графические. Методы геоинформационного анализа позволяют не только проводить математическую обработку данных для оценки транспортной доступности, но и визуализировать ее посредством построения соответствующих тематических карт $[7 ; 11 ; 13]$.

Современный период развития сельских территорий характеризуется сложной динамикой протекающих на них процессов [4; 6; 10], поэтому одной из актуальных проблем является научное обоснование стратегии пространственного развития, где важное место занимает знание транспортной доступности сельских населенных пунктов [8; 12].

При экономико-географическом анализе пространственного развития сельских территорий Волгоградской области важным аспектом является выявление проблем транспортной доступности сельских поселений и отдельных сел, которые представляют собой элементарные единицы управления социально-экономическим развитием. В работе «Региональное развитие: сельская местность» [15] отмечается, что местоположение, структура населенных пунктов, инфраструктура являются факторами антропогенного потенциала терри- 
тории. Они же являются важнейшим свойством сельских территорий. Следовательно, при экономико-географическом анализе необходимо стремиться к формированию информационной базы по размещению населенных пунктов, включая их картографирование, как основных мероприятий в комплексном исследовании сельских территорий.

\section{Объект и методы исследований}

В основе проведения оценки транспортной доступности сельских населенных пунктов региона лежит временной подход, то есть расчет и оценка временных затрат на преодоление расстояния между отдельным селом и центром. Графически такой подход реализуется посредством построения интерполированного растра и изолиний равного времени в пути - изохрон. При оценке временной транспортной доступности были использованы показатели, рекомендованные при разработке «Схемы районной планировки Волгоградской области» $[1 ; 2]$.

Геоинформационный анализ условий транспортной доступности охватывал 2 пространственных уровня: районный и региональный. На районном уровне была изучена транспортная доступность сельских населенных пунктов от центров муниципальных районов, т.е. масштабной единицей анализа являются муниципальные районы Волгоградской области и районные центры, как важнейшие элементы единой системы расселения на сельских территориях [14]. На первом этапе в геоинформационной системе ArcGis была сформирована база данных, включающая позиционные данные сел Волгоградской области (всего 1474 села) и атрибутивные данные временных затрат. Расчет временных затрат в пути основан на районной сети дорог с твердым покрытием и скорости движения 60 км/ч. На следующем этапе с помощью функций пространственного анализа - интерполяция (метод естественная окрестность) был сгенерирован растр значений транспортной доступности, который был проклассифицирован с выделением трех ареалов транспортной доступности сел относительно центров муниципальных районов: а) до 30 минут; б) от 30 до 45 минут; в) более 45 минут.
Второй пространственный уровень включает оценку транспортной доступности сел от областного центра - г. Волгограда, соответственно, масштаб картографирования охватывает территорию всего региона. На первом этапе были дополнены базы данных по селам атрибутивными значениями временных затрат в пути до Волгограда. Расчет времени в пути был проведен с опорой на федеральные автодороги, выходящие лучами из Волгограда. На втором этапе проведена интерполяция значений временной доступности и построен соответствующий растр, который был проклассифицирован по значению временной доступности до областного центра: а) до 2 часов, б) 2-4-часовая доступность, в) более 4 часов. На последнем этапе по полученному растру построены изохроны с интервалом в 1 час.

\section{Результаты исследования}

Анализ данных пространственного анализа сел с разным значение транспортной доступности показывает, что все сельские населенные пункты области делятся по условиям временной транспортной доступности на три группы. Расчеты показывают, что из 1474 сельских населенных пунктов области 308 сел находятся в пределах 30-минутной доступности районных центров, что составляет 20,9 \% в среднем по области. Эти территории можно отнести к благоприятными по условиям доступности. При этом в 12 районах доля сел с такой доступностью выше средне областного показателя. К ним по степени убывания относятся: Среднеахтубинский район $49,1 \%$, Нехаевский - $38 \%$, Киквидзенский $35,3 \%$, Чернышковский - 32,6\%, Фроловский $-31,2 \%$, Руднянский $-26,9 \%$, Алексеевский $-26,7 \%$, Новоаннинский $-25,3 \%$, Котельниковский $-23,5 \%$, Октябрьский $-23,3 \%$, Новониколаевский $-22,4 \%$.

Транспортная доступность от 30 до 45 минут характерна для 371 села, что составляет $25,2 \%$ в среднем по области. Такие условия доступности относятся к ограниченно благоприятным. При этом в 15 районах доля сельских населенных пунктов, находящихся в ограниченно благоприятной зоне доступности районного центра, превышает срденобластной показатель. К числу таких районов от- 


\section{ГЕОГРАФИЯ И ГЕОИНФОРМАТИКА}

носятся по мере убывания: Руднянский район - $50 \%$, Кумылженский - 44,7 \%, Среднеахтубинский $-43,6 \%$, Новоаннинский $-38 \%$, Ольховский $-37,9 \%$, Нехаевский - $34 \%$, Киквидзенский - 32,4 \%, Котовский - 30,8 \%, Ленинский - $30 \%$, Светлоярский - 28,6\%, Урюпинский $-27,9 \%$, Алексеевский - 26,7 \%, Быковский $-25,9 \%$, Дубовский $-25,7 \%$.

Неблагоприятные условия временной транспортной доступности (более 45 минут) наблюдаются у 795 сельских населенных пунктов, что составляет в среднем по области $53,9 \%$. Можно говорить о преобладании этого показателя в расселении области. Отметим по убывающей районы с такими условиями транспортной доступности: Калачевский район - 78,2 \%, Дубовский - 76,9 \%, Николаевский - $75 \%$, Клетский - $75 \%$, Старополтавский - 69,2\%, Октябрьский - 66,7 \%, Палласовский $-66 \%$, Еланский $-65,8 \%$, Жирновский - 64,7\%, Городищенский $64,3 \%$, Котельниковский - 64,2 \%, Новони- колаевский $-63,3 \%$, Быковский $-63 \%$, Иловлинский $-62 \%$, Михайловский - 59,2\%.

Большое значение для экономико-географического анализа сельского расселения области имеет выявление моделей его территориальной структуры. Анализ построенной карты (рис. 1) показывает, что для административных районов области наиболее рациональным является расположение районного центра в середине территории. Причем территория должны иметь компактную форму, близкую к квадрату, или окружности, как, к примеру, в Нехаевском, Кумылженском, Фроловском, Киквидзенском районах. В случае периферийного расположения районных центров, возникает, как правило, значительная зона неблагоприятной транспортной доступности: Чернышковский, Клетский, Николаевский, Быковский, Камышинский, Палласовский, Еланский, Дубовский районы.

Важным показателем социально-экономического единства территории является ус-

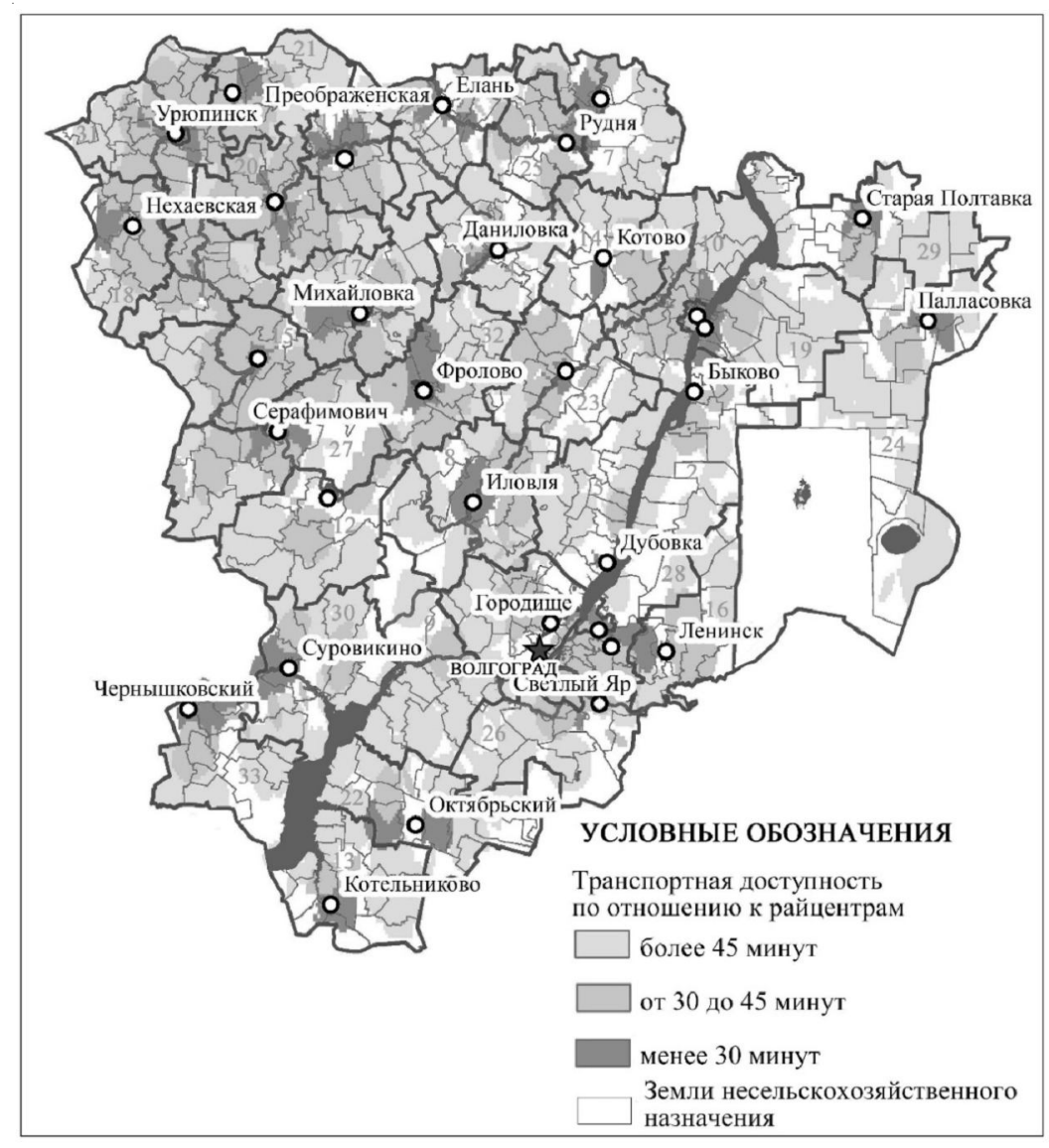

Рис. 1. Условия транспортной доступности сельских территорий Волгоградской области от районных центров 
ловие временной транспортной доступности центра единой системы регионального расселения. При построении карты «Условия транспортной доступности сельских территорий Волгоградской области от областного центра» (рис. 2), как уже было отмечено ранее, были проведены изохроны 1,2 , $3,4,5,6,7$ часовой доступности до областного центра. При экономико-географической оценке мы учитывали следующие показатели: до 2 часов - зона непосредственного влияния Волгограда - это благоприятная зона. Зона 2-4-часовой доступности - ограниченно благоприятный показатель формирующего влияния областного центра, зона транспортной доступности более 4 часов неблагоприятная зона хозяйственного влияния Волгограда.
В целом анализ карты показывает, что в благоприятную зону входят следующие районы: Дубовский, Иловлинский, Калачевский, Городищенский, Светлоярский, Среднеахтубинский, Ленинский районы.

Ограничено благоприятное расположение по отношению к Волгограду проявляется в Камышинском, Ольховском, Фроловском, Михайловском, Серафимовичском, Клетском, Суровикинском, Чернышковском, Котельниковском, Октябрьском, Быковском районах. Остальные 15 районов имеют неблагоприятные условия временной доступности Волгограда.

\section{Заключение}

Выявленные условия временной транспортной доступности районных центров в сель-

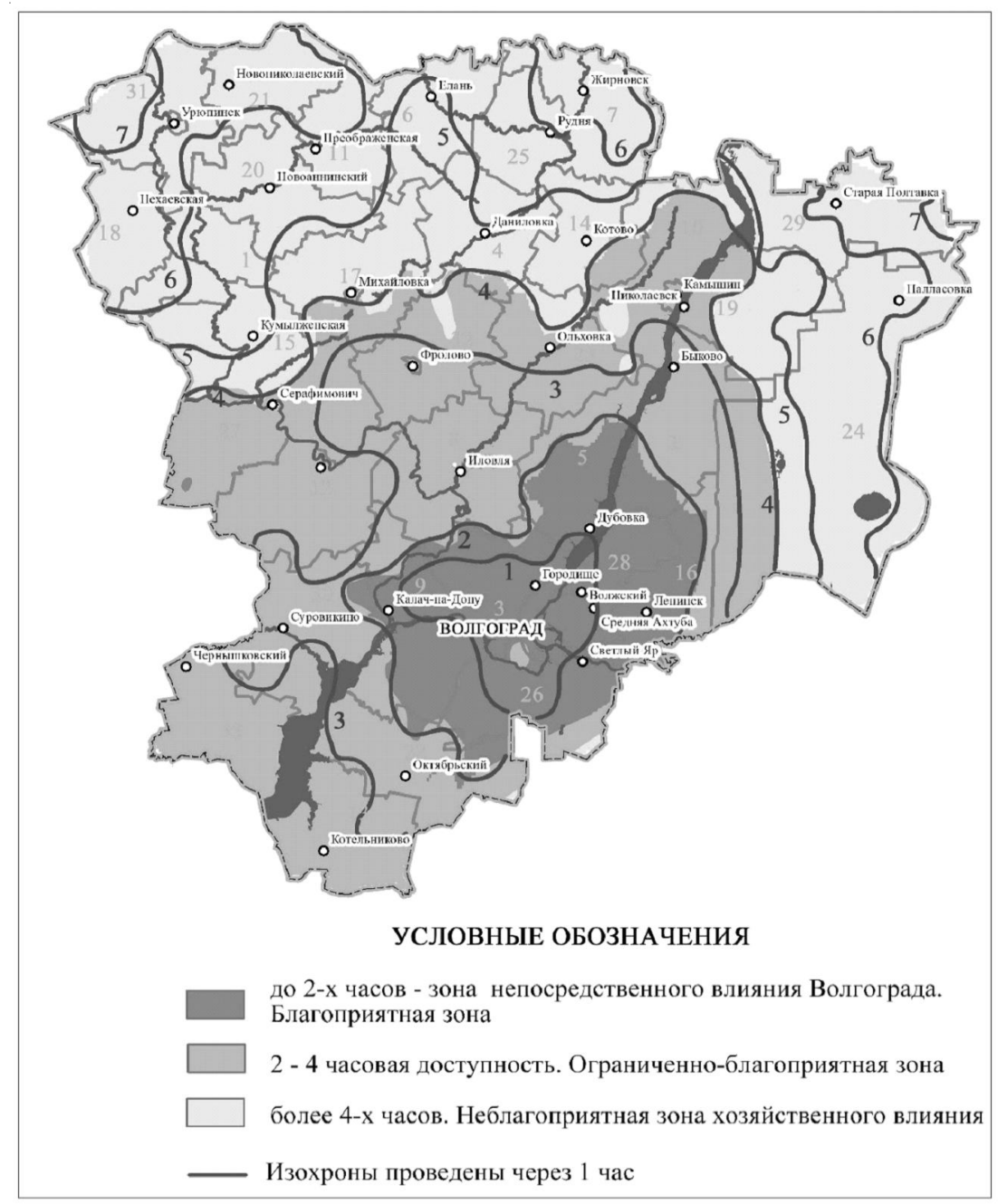

Рис. 2. Условия транспортной доступности сельских территорий Волгоградской области от областного центра 
ских районах показывают значительную неоднородность уровней обеспеченности жителей районов различными услугами, сосредоточенными в центрах. Проведенная работа показывает направления пространственного развития возможных путей повышения социально-экономической деятельности на сельских территориях. Кроме того, характерной чертой территориальной структуры условий временной транспортной доступности является изолированность районных благоприятных и относительно благоприятных зон доступности друг от друга. Смыкание зон наблюдается только в отдельных районах. К примеру, в Среднеахтубинском и Ленинском районах, Николаевского и Быковского районов, Урюпинского и Новониколаевского районов.

Выявленная территориальная структура системы регионального расселения сельского населения позволяет предположить существование значительных проблем социальноэкономического развития из-за высоких транспортных затрат на перевозку произведенной продукции. Могут проявляться проблемы в уровне социального обслуживания уникальными видами обслуживания, сосредоточенных в Волгограде. Рациональным было бы развитие региональных подцентров обслуживания в Урюпинске, Жирновске, Камышине, Палласовке, Котельниково.

\section{ПРИМЕЧАНИЕ}

${ }^{1}$ Работа выполнена при финансовой поддержке Администрации Волгоградской области в рамках соглашения о предоставлении из областного бюджета грантов в форме субсидий № 7 от 29.11.2019.

The reported work was carried out with the financial support of the Administration of Volgograd region in the framework of the agreement on the provision of grants from the regional budget in the form of subsidies No. 7 dated November 29, 2019.

\section{СПИСОК ЛИТЕРАТУРЫ}

1. Аляев, В. А. Транспортная инфраструктура и современная география сел Волгоградской области / В. А. Аляев, М. В. Аляев // Грани познания. - 2014. - № 5 (32). - С. 53-59.

2. Аляев, В. А. Формирование территориальной структуры хозяйства и транспортной инфра- структуры Волгоградского региона (конец XIX конец XX в.) / В. А. Аляев, М. В. Аляев. - Волгоград : Изд-во ВолГУ, 2018. - 203 с.

3. Бадина, С. В. Проблемы транспортной доступности изолированных населенных пунктов европейского сектора арктической зоны России / С. В. Бадина, А. А. Панкратов, К. В. Янков // ИнтерКарто. ИнтерГИС. $-2020 .-$ Т. 26, № 1. - С. 305-318. -DOI: https://doi.org/10.35595/2414-9179-2020-1-26-305-317.

4. Галин, Р. А. Расселение сельского населения как фактор развития сельского хозяйства / Р. А. Галин // Экономика и управление. - 2015. - № 5 (127). C. 28-30.

5. Дубовик, В. О. Методы оценки транспортной доступности территории / В.О. Дубовик // Региональные исследования. - 2013. - № 4 (42). - С. 11-18.

6. Егоров, Д. О. Сельское расселение России: типология территорий по людности сельских населенных пунктов / Д. О. Егоров, В. С. Шурупина // Региональные исследования. - 2018. - № 4 (62). C. 4-16.

7. Ивлиева, Н. Г. Геоинформационно-картографическое обеспечение исследований пространственно-временных особенностей сельского расселения республики Мордовия / Н. Г. Ивлиева, В. Ф. Манухов // ИнтерКарто. ИнтерГИС. 2017. - Т. 23, № 2. - С. 64-77.

8. Куратова, Э. С. Транспортная доступность и повышение социально-экономического статуса территорий европейского северо-востока России / Э. С. Куратова, Н. В. Терешина // Транспортное дело России. - 2019. - № 5. - С. 77-79.

9. Леонов, В. В. Оценка транспортной доступности государственных организаций здравоохранения города Москвы / В. В. Леонов, А. В. Долгушин, С. О. Максимов // Промышленное и гражданское строительство. - 2019. - № 8. - С. 19-23. DOI: https:// doi.org/10.33622/0869-7019.2019.08.19-23.

10. Руднева, О.С.Структурная эволюция сети сельского расселения в регионах степной зоны России / О. С. Руднева, А. А. Соколов // Russian Economic Bulletin. - 2019. - T. 2. - C. 280-285.

11. Тимонин, С. А. Геоинформационные модели расселения населения и их применение / С. А. Тимонин, В. М. Яблоков // ArcReview. 2011. - № 3. - C. 7 .

12. Транспортная доступность как индикатор развития региона / П. А. Лавриненко [и др.] // Проблемы прогнозирования. - 2019. - № 6 (177). C. $136-146$.

13. Хаванская, Н. М. Картографические методы исследования системы сельского расселения Волгоградской области / Н. М. Хаванская, В. А. Аляев, Д. А. Семенова // Природные системы и ресурсы. - 2019. - Т. 9, № 4. - С. 64-71. - DOI: https:// doi.org/10.15688/nsr.jvolsu.2019.4.7. 
14. Хаванская, Н. М. Оценка условий транспортной доступности сельских территорий Волгоградской области / Н. М. Хаванская, С. С. Шинкаренко // Геоинформационное картографирование в регионах России : материалы XI Всерос. науч.-практ. конф. - Воронеж : [б. и.], 2020. - С. 347-350.

15. Чепурных, Н. В. Региональное развитие: сельская местность / Н. В. Чепурных, А. Л. Новоселов, А. В. Мерзлов. - М. : Наука, 2006. - 490 с.

16. Estimation of transport accessibility of the capital economic region / O. Matiychyk [et al.] // Eastern-European Journal of Enterprise Technologies. - 2017. - T. 2, № 3 (86). - C. 31-40. DOI: $10.15587 / 1729-4061.2017 .98118$.

17. Pitts, F. R. A Graph Theoretic Approach to Historical Geography / F. R. Pitts // Prof. Geogr. - 1965. № 17 (5). - P. 15-20.

\section{REFERENCES}

1. Alyaev V.A., Alyaev M.V. Transportnaya infrastruktura i sovremennaya geografiya sel Volgogradskoy oblasti [Transport Infrastructure and Modern Geography of the Villages of the Volgograd Region]. Grani poznaniya, 2014, no. 5 (32), pp. 53-59.

2. Alyaev V.A., Alyaev M.V. Formirovanie territorialnoy struktury hozyaystva i transportnoy infrastruktury Volgogradskogo regiona (konets $X I X$ - konets $X X$ v.) [Formation of the Territorial Structure of the Economy and Transport Infrastructure of the Volgograd Region (End of the Nineteenth and End of the Twentieth Century)]. Volgograd, Izd-vo VolGU, 2018.203 p.

3. Badina S.V., Pankratov A.A., Yankov K.V. Problemy transportnoi dostupnosti izolirovannykh naselennykh punktov evropeiskogo sektora arkticheskoi zony Rossii [Problems of transport accessibility of isolated settlements in the European sector of the Arctic zone of Russia]. InterKarto. InterGIS, 2020, vol. 26, no. 1, pp. 305-318. DOI: https:/ /doi.org/10.35595/2414-9179-2020-1-26-305-317.

4. Galin R.A. Rasselenie selskogo naseleniya kak faktor razvitiya selskogo hozyaystva [The Settlement of the Rural Population as a Factor in the Development of Agriculture]. Ekonomika i upravlenie, 2015, no. 5 (127), pp. 28-30.

5. Dubovik V.O. Metody otsenki transportnoi dostupnosti territorii [Methods for assessing the transport accessibility of the territory]. Regionalnye issledovaniya, 2013, no. 4 (42), pp. 11-18.

6. Egorov D.O., Shurupina V.S. Selskoe rasselenie Rossii: tipologiya territoriy po lyudnosti selskih naselennyh punktov [Rural Settlement of Russia: Typology of Territories by Population of Rural Settlements]. Regionalnye issledovaniya, 2018, no. 4(62), pp. 4-16.
7. Ivlieva N.G., Manukhov V.F. Geoinformatsionnokartograficheskoe obespechenie issledovaniy prostranstvenno-vremennykh osobennostey selskogo rasseleniya respubliki Mordoviya [Geoinformation-Cartographic Support for Studies of the Spatio-Temporal Features of Rural Settlement of the Republic of Mordovia]. InterKarto. InterGIS, 2017, vol. 23, no. 2, pp. 64-77.

8. Kuratova, E.S., Tereshina N.V. Transportnaya dostupnost' i povyshenie sotsial'noekonomicheskogo statusa territorii evropeiskogo severo-vostoka Rossii [Transport accessibility and improving the socio-economic status of the territories of the European northeast of Russia]. Transportnoe delo Rossii, 2019, no. 5, pp. 77-79.

9. Leonov V.V., Dolgushin A.V., Maksimov S.O. Otsenka transportnoi dostupnosti gosudarstvennykh organizatsii zdravookhraneniya goroda Moskvy [Assessment of transport accessibility of public health organizations in Moscow]. Promyshlennoe $i$ grazhdanskoe stroitel'stvo, 2019, no. 8, pp. 19-23. DOI: https://doi.org/10.33622/0869-7019.2019.08.19-23.

10. Rudneva O.S., Sokolov A.A. Strukturnaya evolyutsiya seti selskogo rasseleniya $\mathrm{v}$ regionah stepnoy zony Rossii [Structural Evolution of the Rural Settlement Network in the Regions of the Steppe Zone of Russia]. Russian Economic Bulletin, 2019, vol. 2, pp. 280-285.

11. Timonin S.A. Geoinformatsionnye modeli rasseleniya naseleniya $\mathrm{i}$ ih primenenie [Geoinformation Models of Population Distribution and Their Application]. ArcReview, 2011, no. 3, p. 7.

12. Lavrinenko P.A., Romashina A.A., Stepanov P.S., Chistyakov P.A. Transportnaya dostupnost' kak indikator razvitiya regiona [Transport accessibility as an indicator of regional development]. Problemy prognozirovaniya, 2019, no. 6 (177), pp. 136-146.

13. Khavanskaya N.M., Alyaev V.A., Semenova D.A. Kartograficheskie metody issledovaniya sistemy sel'skogo rasseleniya volgogradskoi oblasti [Cartographic methods of research of the rural settlement system of the Volgograd region. Prirodnye sistemy i resursy, 2019, Vol. 9, no 4, pp. 64-71.

14. Khavanskaya N.M., Shinkarenko S.S. Otsenka uslovii transportnoi dostupnosti sel'skikh territorii Volgogradskoi oblasti [Assessment of the conditions of transport accessibility of rural areas of the Volgograd region]. Geoinformatsionnoe kartografirovanie $v$ regionakh Rossii: materialy XI Vserossiiskoi nauchno-prakticheskoi konferentsii [Geoinformation mapping in the regions of Russia: materials of the XI All-Russian scientific and practical conference]. Voronezh, [s. n.], 2020, pp. 347-350.

15. Chepurnykh N.V., NovoselovA. L., MerzlovA. V. Regional'noe razvitie: sel'skaya mestnost' [Regional 


\section{ЭкоЛОГия и БИоЛОГИя}

development: countryside]. Moscow, nauka Publ., 2006. $490 \mathrm{p}$.

16. Matiychyk O., Babenko A., Yanovsky P., Sulyma L. Estimation of transport accessibility of the capital economic region. Eastern-European Journal of Enterprise Technologies, 2017, vol. 2, no. 3 (86), pp. 31-40. DOI: 10.15587/1729-4061.2017.98118.

17. Pitts F.R. A Graph Theoretic Approach to Historical Geography. Prof. Geogr., 1965, no. 17 (5), pp. 15-20.

\section{Information About the Authors}

Natalya M. Khavanskaya, Candidate of Sciences (Geography), Associate Professor, Department of Geography and Cartography, Volgograd State University, Prosp. Universitetsky, 100, 400062 Volgograd, Russian Federation, khavanskaya@volsu.ru

Vladimir A. Alyaev, Candidate of Sciences (Geography), Associate Professor, Department of Geography and Cartography, Volgograd State University, Prosp. Universitetsky, 100, 400062 Volgograd, Russian Federation, alyaev@volsu.ru

Diana A. Semenova, Senior Lecturer, Department of Geography and Cartography, Volgograd State University, Prosp. Universitetsky, 100, 400062 Volgograd, Russian Federation, semenova@volsu.ru

\section{Информация об авторах}

Наталья Михайловна Хаванская, кандидат географических наук, доцент кафедры географии и картографии, Волгоградский государственный университет, просп. Университетский, 100, 400062 г. Волгоград, Российская Федерация, khavanskaya@volsu.ru

Владимир Алексеевич Аляев, кандидат географических наук, доцент кафедры географии и картографии, Волгоградский государственный университет, просп. Университетский, 100, 400062 г. Волгоград, Российская Федерация, alyaev@volsu.ru

Диана Александровна Семенова, старший преподаватель кафедры географии и картографии, Волгоградский государственный университет, просп. Университетский, 100, 400062 г. Волгоград, Российская Федерация, semenova@volsu.ru 